\title{
Manganese superoxide dismutase activity in the rat adrenal
}

\author{
F S Raza, M Okamoto ${ }^{1}$, H Takemori ${ }^{1}$ and G P Vinson \\ School of Biological Sciences, Queen Mary, University of London, London E1 4NS, UK \\ ${ }^{1}$ Department of Biochemistry and Molecular Biology, Graduate School of Medicine (H-1), and Laboratories for Biomolecular Networks, \\ Graduate School of Frontier Biosciences, Osaka University 2-2 Yamadaoka, Suita, Osaka, 565-0871 Japan \\ (Requests for offprints should be addressed to G P Vinson; Email: g.p.vinson@qmul.ac.uk)
}

\begin{abstract}
In the light of studies suggesting that transcription of the gene coding for manganese superoxide dismutase (MnSOD) is induced by ACTH in the rat adrenal gland, northern blot analysis was used to determine its mRNA distribution. It was found that mRNA coding for MnSOD is primarily present in the inner zones of the rat adrenal cortex, and not the glomerulosa. To investigate the functional relationships between MnSOD activity and expression and adrenocortical function, adrenals and blood were taken from animals pretreated with corticotrophin or betamethasone (Betnesol), or subjected to a low-sodium diet. MnSOD activity in inner zone mitochondrial fractions was enhanced by corticotrophin and by a low-sodium diet, but suppressed by betamethasone. Apparent cytosolic MnSOD activity, total cytosolic MnSOD and CuZnMnSOD, and glomerulosa mitochondrial MnSOD all were
\end{abstract}

unaffected. Steroid assays showed a clear correlation between circulating corticosterone and inner zone mitochondrial MnSOD, but none between aldosterone and glomerulosa MnSOD.

Immunoblot analysis of MnSOD showed two apparent isoforms, at approximately $25 \mathrm{kDa}$ and $75 \mathrm{kDa}$. There was a partial relationship between expression of the $75 \mathrm{kDa}$ isoform and MnSOD activity, in that it was induced by corticotrophin. However, there was also a slight induction with betamethasone, and a low-sodium diet had no effect. The $25 \mathrm{kDa}$ MnSOD isoform was unaffected by the treatments. The results suggest that $\mathrm{MnSOD}$ may have a specific role in the steroidogenic function of the fasciculata/reticularis of the rat adrenal, but not in that of the glomerulosa.

Journal of Endocrinology (2005) 184, 77-84

\section{Introduction}

The relationship between redox status and adrenocortical function has been the object of speculation since the discovery that ascorbic acid depletion is an early response to corticotrophin (ACTH) stimulation, and this has been used as a sensitive and highly specific bioassay for corticotrophin (Sayers et al. 1948, Chayen et al. 1976). Several attempts have been made to interpret this in functional terms (Kitabchi 1967, Hornsby et al. 1985, Yanagibashi et al. 1990). In this respect, the finding that manganese superoxide dismutase (MnSOD) gene transcription may be specifically enhanced by corticotrophin stimulation lends support to the concept of a physiological role (Suwa et al. 2000).

Superoxide dismutases (SODs) are antioxidants that protect the cell from cytotoxic reactive oxygen species (ROS; McCord \& Fridovich 1969). ROS are generated as byproducts of metabolic oxidation, causing extensive cellular injury. In mammals, the cytosolic CuZnSOD and the mitochondrial MnSOD (Weisiger \& Fridovich 1973a, b) are part of a cascade of components within the cell's defensive machinery that inactivate these damaging radicals. It is possible that steroid-producing organs, such as the adrenal cortex, may require additional protection, as steroidogenesis is known to produce unwanted byproducts that may indeed be toxic. These include isocaproic aldehyde, derived from the cholesterol side chain discarded by the action of CYP11A, and free radicals that may be generated by 'leaky' P450s. It has been suggested that enzymes such as the aldose reductase-like AKR1B7 and $\mathrm{MnSOD}$ may be present in steroidogenic tissues for this reason (Sahut-Barnola et al. 2000, Suwa et al. 2000).

There may be alternative interpretations. Recent studies have also recognised that ROS may act as intracellular signalling molecules, suggesting that the SODs may have roles in cell signalling, with critical roles in cellular senescence, growth and apoptosis (Gamaley \& Klyubin 1999).

Finally, Suwa and co-workers (2000) have proposed that ACTH induces an imbalance between MnSOD and glutathione peroxidase, resulting in the formation of excess hydrogen peroxide, which they postulate may contribute to the downregulation of CYP11B2 and aldosterone synthesis in the glomerulosa. 
The present paper describes studies on the distribution and regulation of MnSOD expression in rat adrenal tissue, aimed at further interpretation of its function.

\section{Materials and Methods}

\section{Animals and tissue preparation}

Adult male Wistar rats $12-14$ weeks old and weighing 180-220 g were obtained from commercial suppliers, and maintained briefly at Queen Mary, University of London under standard conditions of light and temperature, in accordance with appropriate guidelines for animal care. Rats were maintained on a diet of wholemeal flour (Sainsburys Ltd, UK) supplemented with $1 \% \mathrm{CaCO}_{3}$ and $1 \% \mathrm{NaCl}$, with access to distilled water for 3 weeks. The low-sodium diet omitted the $1 \% \mathrm{NaCl}$. ACTH-treated animals were injected subcutaneously with $100 \mu \mathrm{g}$ Depot Synacthen (Ciba-Geigy) on 5 days, and rats treated with betamethasone (Betnesol, Glaxo-Wellcome) were given $25 \mathrm{ml}$ distilled water supplemented with $0.05 \mathrm{~g}$ betamethasone daily for 7 days. For confirmation of the actions of the treatments, blood was collected for steroid assay. Rats were pretreated with heparin (1000 units/animal), then killed by stunning and cervical dislocation. Blood was collected from major vessels, centrifuged at $3000 \mathrm{~g}$ for $10 \mathrm{~min}$, and plasma was frozen for storage. Adrenals were snap-frozen and stored in liquid nitrogen. When required, zona glomerulosa (with capsule) and zona fasciculata/ reticularis (with medulla) fractions were separated under pressure between two glass plates.

\section{Steroid assays}

Plasma corticosterone and aldosterone concentrations were assayed using kits provided by Diagnostic Systems Laboratories Inc. (Webster, TX, USA).

\section{Northern blot analysis}

Total RNA was extracted from the zona glomerulosa and inner zones (with medulla) from rat adrenals as described before (Halder et al. 1998). RNAs $(10 \mu \mathrm{g})$ were separated by electrophoresis and transferred on to a nylon membrane, Hybond-N+ (Amersham). Membranes were hybridised with $\left[{ }^{32} \mathrm{P}\right]$-labelled MnSOD cDNA screened and isolated from a rat adrenal cDNA library, the housekeeping gene glyceraldehyde-3-phosphate dehydrogenase (G3 PDH), and the zona glomerulosa and fasciculata/ reticularis-specific markers, preadipocyte factor-1 (Pref-1) and inner zone antigen (IZ-Ag) (Halder et al. 1998, Raza et al. 2001), in $5 \times \mathrm{SSPE}$ containing $50 \%$ formamide, $0 \cdot 5 \%$ $(\mathrm{w} / \mathrm{v}) \mathrm{SDS}, 0 \cdot 1 \%(\mathrm{w} / \mathrm{v})$ polyvinylpyrrolidone, $0 \cdot 1 \%(\mathrm{w} / \mathrm{v})$ Ficoll and $0 \cdot 1 \%(\mathrm{w} / \mathrm{v})$ BSA at $42{ }^{\circ} \mathrm{C}$ for $16 \mathrm{~h}$. After hybridisation, the membranes were washed sequentially in
$2 \times \operatorname{SSPE} / 0 \cdot 1 \%(\mathrm{w} / \mathrm{v}) \mathrm{SDS}, 1 \times \mathrm{SSPE} / 0 \cdot 1 \%(\mathrm{w} / \mathrm{v}) \mathrm{SDS}$, and $0.2 \times \mathrm{SSPE} / 0 \cdot 1 \%(\mathrm{w} / \mathrm{v})$ SDS at $60{ }^{\circ} \mathrm{C}$, and then exposed to X-ray film (Amersham) at $-80{ }^{\circ} \mathrm{C}$ with an intensifying screen.

\section{Subcellular fractionation}

For subcellular fractionation, adrenals were placed in 0.05 $\mathrm{M}$ potassium phosphate buffer (PBS) $\mathrm{pH} \quad 7 \cdot 8$. Capsule/glomerulosa and inner zone fractions were separated and homogenised in PBS on ice. Samples were subjected to subcellular centrifugation, the nuclear pellet was removed at $800 \mathrm{~g}\left(15 \mathrm{~min}\right.$ at $\left.4{ }^{\circ} \mathrm{C}\right)$, the supernatant centrifuged at $12000 \mathrm{~g}\left(15 \mathrm{~min}\right.$ at $\left.4{ }^{\circ} \mathrm{C}\right)$ and the mitochondrial pellet and the membrane/cytosolic supernatant fractions were retained. The mitochondrial pellet was

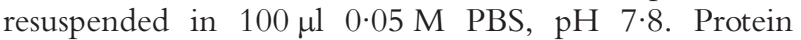
content for both the mitochondrial and cytosolic/ membrane fractions was determined by the method of Lowry et al. (1951). Both samples were divided into two aliquots, for total SOD activity and for MnSOD activity after inhibition of CuZnSOD.

\section{SOD activity studies}

The xanthine-xanthine oxidase nitroblue tetrazolium (NBT) assay (Spitz \& Oberley 1989) provides an indirect measurement of SOD activity. This measurement of total SOD (CuZnSOD and MnSOD) and MnSOD activity alone is based on a modification of the method described by White et al. (1993).

\section{Inhibition of CuZnSOD activity by diethyldithiocarbamate}

The mitochondrial and membrane/cytosol aliquots were treated with $50 \mathrm{mM}$ diethyldithiocarbamate (DDC) for $1 \mathrm{~h}$ at $30^{\circ} \mathrm{C}$, inactivating CuZnSOD activity. The samples were dialysed using three changes of 400 volumes of $50 \mathrm{mM}$ PBS buffer $\mathrm{pH} 7 \cdot 8$ with $0 \cdot 1 \mathrm{mM}$ EDTA for $12-16 \mathrm{~h}$ at $4{ }^{\circ} \mathrm{C}$. Dialysed samples were then assayed for MnSOD activity.

\section{Spectrophotometric analysis of SOD activity}

Assays for total and MnSOD activity in the different cell fractions from the treated animals were carried out in $1 \mathrm{ml}$ aliquots with different amounts of protein, from 0 to $100 \mu \mathrm{g}$. The assay mixture contained the following reactants: $1 \mathrm{mM}$ DTPA, 1 unit catalase, $5.6 \times 10^{-5} \mathrm{M}$ NBT, $10^{-4} \mathrm{M}$ xanthine, $0.13 \mathrm{mg} / \mathrm{ml}$ BSA, $50 \mu \mathrm{M}$ bathocuproinedisulphonic acid, $0.025 \%$ Triton X-100 and xanthine oxidase (an amount sufficient to achieve an absorbance rate change of 0.025 absorbance units $/ \mathrm{min}$ at $560 \mathrm{~nm}$ ). The assay depends on the inhibition of the xanthine oxidase by SOD activity in added tissue samples. Homogenates were assayed for total SOD activity 
$(\mathrm{CuZnSOD}+\mathrm{MnSOD})$ and MnSOD activity alone (after inactivation of CuZnSOD with DDC).

Data were plotted as percentage xanthine oxidase inhibition against added tissue protein concentration, and 1 unit of activity was defined as the amount of protein required to decrease the reference rate by $50 \%$ of maximum inhibition. Results were expressed as units of activity per mg protein.

\section{SDS-PAGE gel electrophoresis}

Protein fractions were subjected to SDS-PAGE. A vertical slab gel electrophoresis unit (Biorad) incorporating a discontinuous (multiphasic) buffer system was used. The stacking gel (pH 6.8, Tris $125 \mathrm{mM}, 4 \%$ (w/v) acrylamide/ bisacrylamide, $0 \cdot 1 \%(\mathrm{w} / \mathrm{v}) \mathrm{SDS})$ was polymerised on top of the resolving gel $(\mathrm{pH} 8 \cdot 8$, Tris $375 \mathrm{mM}, 12 \%$ (w/v) acrylamide/bisacrylamide, $0 \cdot 1 \% \quad(\mathrm{w} / \mathrm{v})$ SDS). Protein samples were loaded onto the stacking gel. Gel electrophoresis was run in a reservoir buffer $(\mathrm{pH} 8 \cdot 3$, Tris $25 \mathrm{mM}$, glycine $192 \mathrm{mM}$, SDS $(0 \cdot 1 \%(\mathrm{w} / \mathrm{v}))$ at $35 \mathrm{~V}$ overnight and then increased to $200 \mathrm{~V}$ for $3-4 \mathrm{~h}$ at $4{ }^{\circ} \mathrm{C}$. Prestained SDS-PAGE molecular weight standards (14-200 kDa; Amersham International plc) were run on each gel.

After electrophoresis, the gel was equilibrated in transfer

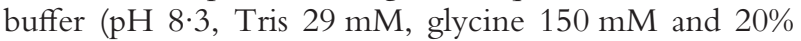
(v/v) methanol) for $30 \mathrm{~min}$. The separated proteins were electrotransferred to Hybond-enhanced chemiluminescence (ECL) nitrocellulose membrane (Amersham) in transfer buffer at $4{ }^{\circ} \mathrm{C}$ using a Transphor unit at $35 \mathrm{~V}$ overnight or $100 \mathrm{~V}$ for $2-3 \mathrm{~h}$ at $4^{\circ} \mathrm{C}$. Transfer to polyvinylidene difluoride membranes required that the membranes be rinsed in methanol for $1 \mathrm{~min}$, then washed for $10 \mathrm{~min}$ in transfer buffer before electrotransfer as described above. Membranes were removed and rinsed in Tween buffer $(150 \mathrm{mM} \mathrm{NaCl}, 10 \mathrm{mM}$ Tris- $\mathrm{HCl} \mathrm{pH} 7 \cdot 6$ and $0.05 \%$ Tween 20) twice for $15 \mathrm{~min}$, removing excess glycine and methanol. Membranes were then subjected to immunoblotting.

\section{Immunoblotting}

Membranes with the transferred protein were blocked for $2 \mathrm{~h}$ in Tween buffer with $5 \%$ casein and $0.1 \%$ sodium azide at room temperature. Membranes were incubated with a rabbit anti-rat MnSOD polyclonal antibody (1:500; generous gift from Professor Naoyuki Taniguchi at Osaka University Medical School) in blocking buffer with $0 \cdot 3 \%$ BSA overnight at $4{ }^{\circ} \mathrm{C}$. Membranes were washed in Tween buffer three times for a total of $30 \mathrm{~min}$ before the addition of a secondary swine anti-rabbit horseradishperoxidase-linked antibody (Amersham) diluted 1:1000 in Tween buffer with $1 \%$ casein for $1.5 \mathrm{~h}$ at room temperature. The secondary antibody was removed and the membrane washed in Tween buffer for $45 \mathrm{~min}$; the solution was changed at 10-min intervals at room temperature. Luminescent bands were developed using the ECL (Amersham) reagents, and visualised using Hyperfilm-ECL (Amersham).

\section{Statistical analysis}

Student's $t$-test with Bonferroni correction and Pearson's method for calculation of correlation were used as appropriate.

\section{Results}

\section{Northern blot analysis of MnSOD $m R N A$}

RNA extracted from the zona glomerulosa and inner zones (with medulla) were hybridised with ${ }^{32} \mathrm{P}$-labelled cDNA probes for IZ-Ag, MnSOD, Pref-1 and the housekeeping gene, G3 PDH (Fig. 1). Using Pref-1 as a zona-glomerulosa-specific control (expression in the inner zones derives from the medulla, in which Pref- 1 is also present) and IZ-Ag as inner zone marker, it was shown that MnSOD was localised to the inner zones (Fig. 1).

\section{Regulation of MnSOD in the rat adrenal}

The effects of ACTH pretreatment, low dietary sodium and betamethasone were studied, as these treatments have well recorded effects on both structure and function of the zona glomerulosa and inner zones (Vinson et al. 1992). Adrenal weights after treatment were (mean \pm S.E.M.): controls $52.2 \pm 5.5 \mathrm{mg}$, ACTH-treated $72.8 \pm 3.6 \mathrm{mg}$ $(P<0 \cdot 01$ compared with controls, $t$-test with Bonferroni correction), low-sodium diet $65.2 \pm 2.5 \mathrm{mg}$, betamethasone $43.5 \pm 3.9 \mathrm{mg}$. The effectiveness of the treatments is best illustrated by the changes in circulating steroid concentration: ACTH significantly stimulated corticosterone, and aldosterone was increased in the animals fed a low-sodium diet. ACTH also marginally increased aldosterone concentrations, whereas both steroids were reduced by betamethasone (Fig. 2).

\section{$\mathrm{MnSOD}$ activity}

Values for mitochondrial MnSOD activity, compared with total SOD (not shown), confirmed that MnSOD in fact accounts for virtually all the SOD activity assayed in these preparations. In inner zone mitochondria, ACTH pretreatment produced a significant increase in MnSOD activity, and a smaller but still significant increase in inner zone mitochondrial MnSOD was also seen in the animals fed a low-sodium diet. Betamethasone had no significant effect (Fig. 3). Total MnSOD (MnSOD with $\mathrm{CuZnSOD)}$ in the cytosolic fraction was unaffected by 


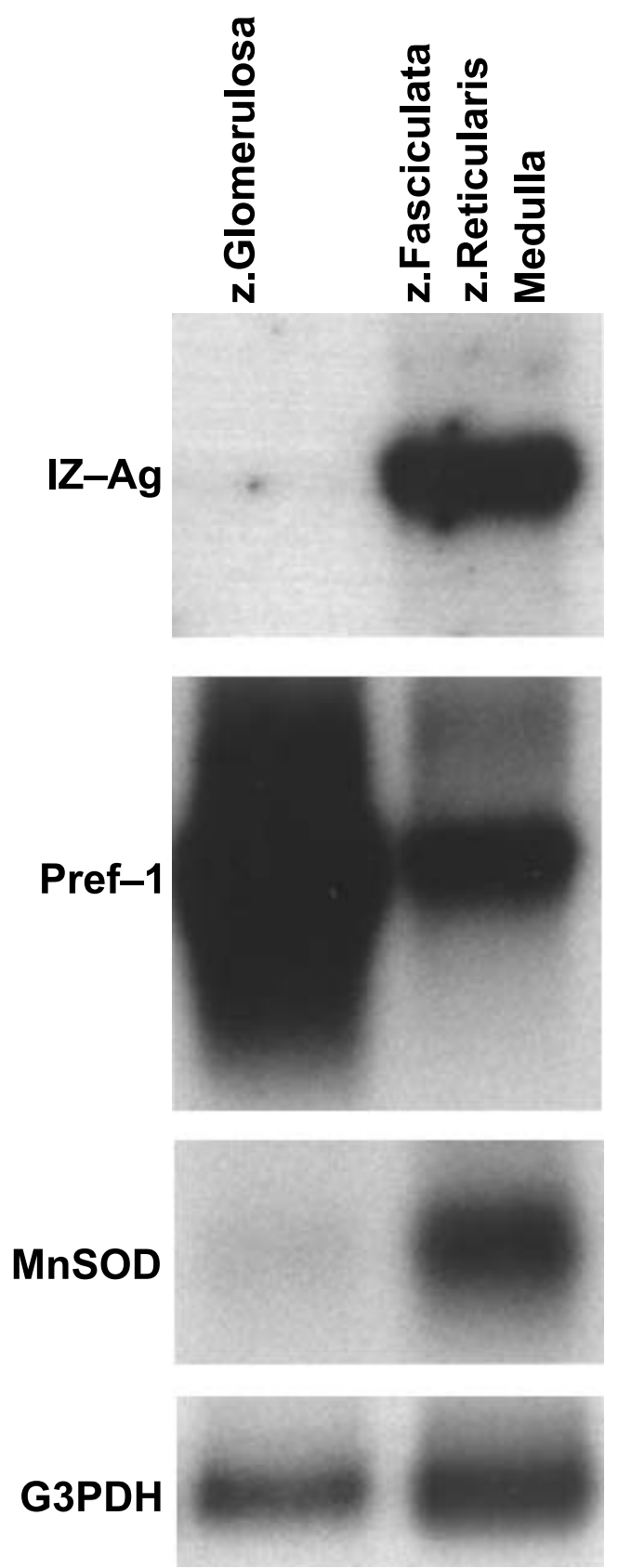

Figure 1 Northern blot analysis. Total RNA was isolated from the zona (z.) glomerulosa and inner zones of the rat adrenal, and hybridised with ${ }^{32} \mathrm{P}$-labelled cDNA probes for MnSOD, the inner zone antigen (IZ-Ag), preadipocyte factor 1 (Pref-1) and G3PDH. The results show a clear zonal distribution of these components: $\mathrm{MnSOD}$, like IZ-Ag, is primarily transcribed in the inner zones, whereas Pref- 1 is in zona glomerulosa.

any of the treatments (Fig. 4). Data for glomerulosa fraction mitochondrial MnSOD showed that activity was low at all times, and not significantly affected by the treatments (Fig. 3).
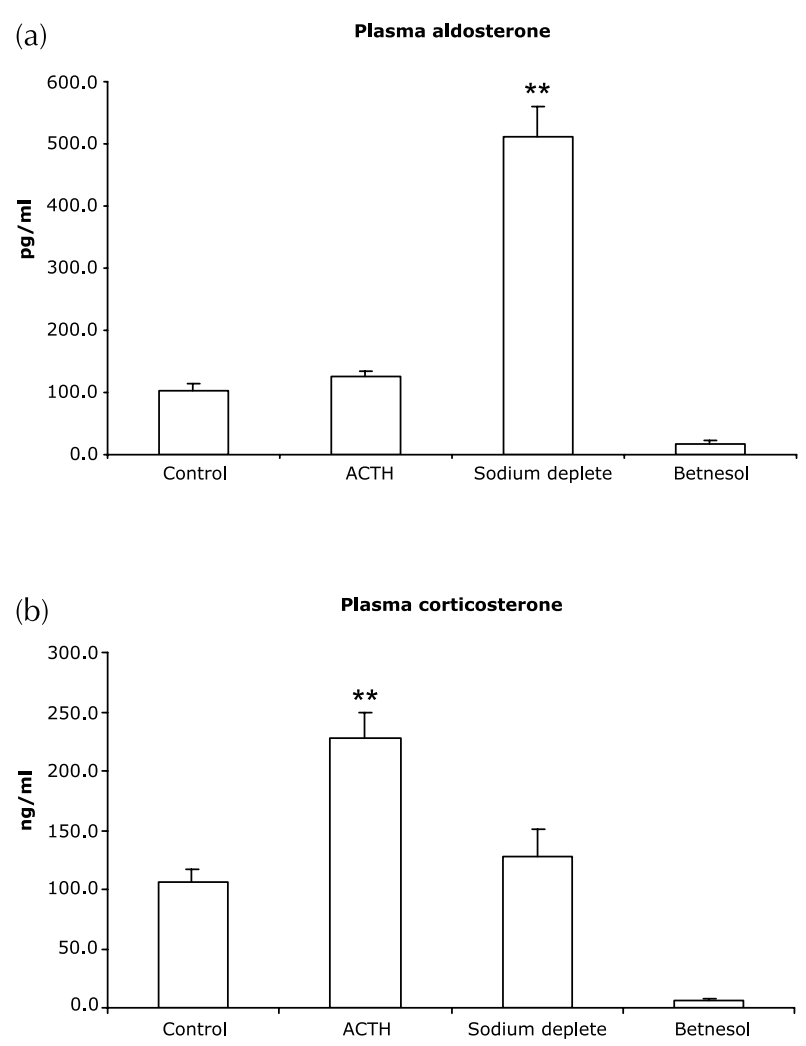

Figure 2 Concentrations of (a) aldosterone and (b) corticosterone in plasma from control (untreated) animals, and from animals pretreated with corticotrophin (ACTH) or betamethasone (Betnesol), or fed a low-sodium diet (sodium deplete). Corticosterone was significantly enhanced by ACTH, and aldosterone by a low-sodium diet; both were suppressed by betamethasone (comparison with untreated controls: ${ }^{*} P<0 \cdot 01$, $t$-test with Bonferroni correction, $n=6$ throughout).

There was a clear correlation between circulating plasma corticosterone concentrations and inner zone MnSOD activity, but none between plasma aldosterone and glomerulosa fraction MnSOD (Fig. 5).

\section{Immunoblotting analysis}

To relate activity with protein expression, immunoblotting analysis was performed on SDS gels of inner zone mitochondrial protein. In both glomerulosa and inner zone fractions, two bands were revealed, of approximately $25 \mathrm{kDa}$ and $75 \mathrm{kDa}$ (Fig. 6). The $25 \mathrm{kDa}$ band was unaffected by any of the treatments, but the $75 \mathrm{kDa}$ band changed in a manner that partly correlated with the activity studies, in that it was increased by ACTH pretreatment, but there was no change in the animals fed a low-sodium diet. Betamethasone also produced a modest increase in this component. 
(a)

MnSOD activity/inner zones

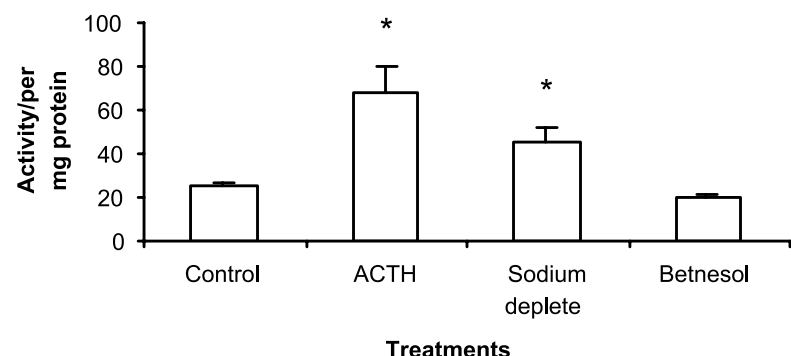

(b) MnSOD activity /capsule,glomerulosa

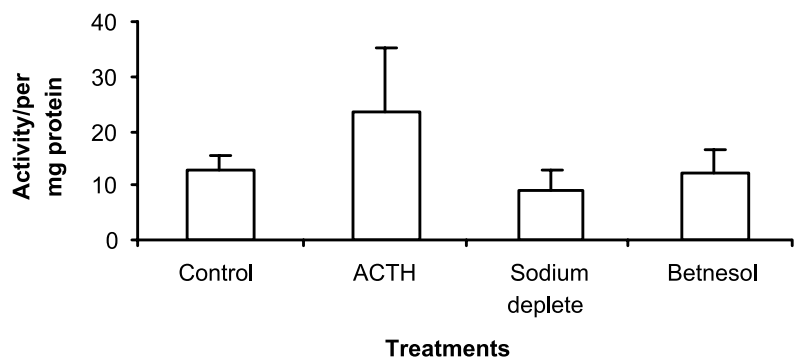

Figure 3 Mitochondrial MnSOD activity in (a) inner zones and (b) glomerulosa. In inner zones, MnSOD activity was enhanced by ACTH and by a low-sodium diet (sodium deplete; comparison with untreated controls: ${ }^{*} P<0 \cdot 05$, $t$-test with Bonferroni correction, $n=6$ throughout). Betamethasone (Betnesol) had no effect.

Mitochondrial MnSOD activity in glomerulosa fractions was not significantly affected by any of the treatments.

\section{Discussion}

The sensitivity and specificity of the adrenocortical response to corticotrophin and, in the present context, the exquisite tissue specificity of the redox response, has been reported over 50 years, and the present results extend this series of studies (Sayers et al. 1948, Kitabchi 1967, Chayen et al. 1976, Hornsby et al. 1985, Yanagibashi et al. 1990). In demonstrating the corticotrophin-dependence of the transcription, expression and activity of MnSOD specifically in the zonae fasciculata/reticularis of the rat adrenal, the results presented here extend those of Suwa et al. (2000), who showed induction of MnSOD transcription by corticotrophin; similar findings in bovine adrenocortical cells were reported by Chinn et al. (2002).

There are several different possible interpretations of the significance of MnSOD distribution and activity in the rat adrenal. One is that the zonal specificity of MnSOD expression (Fig. 1) reflects the very much greater capacity for steroidogenesis, and P-450 mediated oxidation, in the fasciculata/reticularis. Accordingly, it could be that the induction of MnSOD is a purely protective device. With increased steroidogenesis, leakage of electrons from the adrenal mitochondrial electron transport chain may be
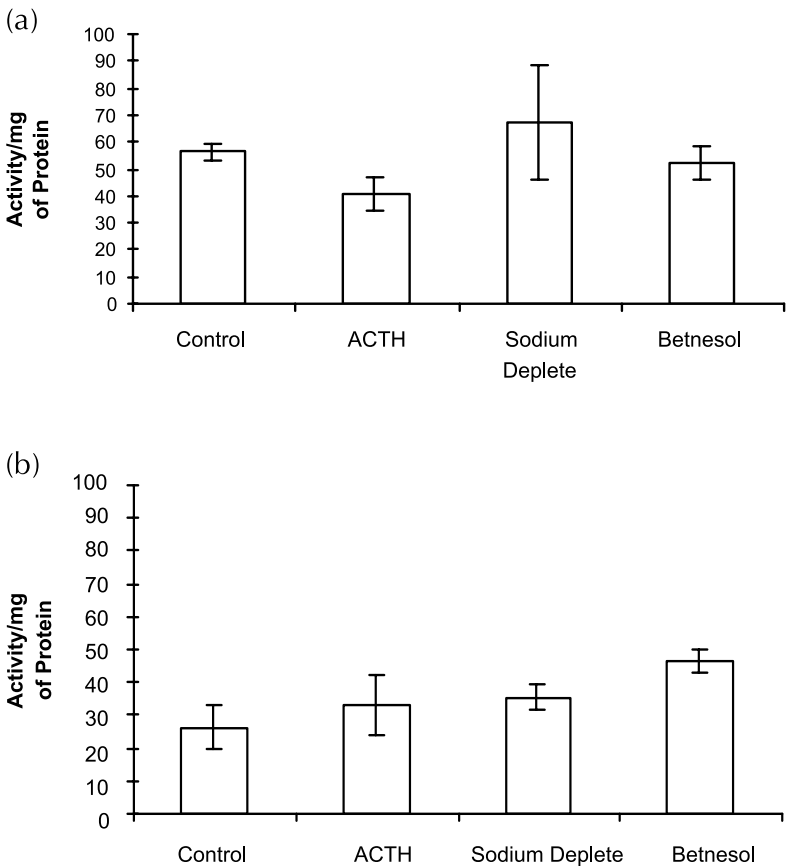

Figure 4 (a) Cytosolic CuZnSOD plus apparent cytosolic MnSOD activity and (b) apparent cytosolic MnSOD activity in rat adrenocortical inner zones. These activities were unaffected by all the treatments. Sodium Deplete, low-sodium diet; Betnesol, betamethasone.

enhanced, generating oxygen radicals (Hanukoglu \& Rapoport 1995). Hence adrenocortical MnSODs may be critical in catalysing the dismutation of the ROS to hydrogen peroxide, which in turn would be detoxified to water by glutathione peroxidase or catalase. Others (Azhar et al. 1995) also have considered MnSOD to be related to steroidogenesis, although they assumed that its role was in cholesterol transport.

On the basis of the assumption that ROS are inherently toxic, Suwa et al. (2000) postulated that the known downregulation of aldosterone synthase brought about by extended corticotrophin treatment might be attributed to increased ROS generation in the glomerulosa. This is less plausible, however, when it is recalled that MnSOD is only one fraction of available SOD activity, and $\mathrm{CuZnSOD}$ and soluble SOD are expressed throughout the gland and appear to be unaffected by the treatments (Fig. 4). Moreover, although ACTH, and to a lesser extent betamethasone, stimulated expression of the $75 \mathrm{kDa}$ MnSOD isoform in glomerulosa preparations, this was not associated with significant changes in MnSOD activity in the glomerulosa fraction (Fig. 3). Indeed, the evidence for MnSOD in this fraction could well be accounted for by the inevitable fasciculata contamination of this fraction. Finally, there was no correlation, either positive or negative, between plasma aldosterone and glomerulosa mitochondrial MnSOD activity (Fig. 5). 


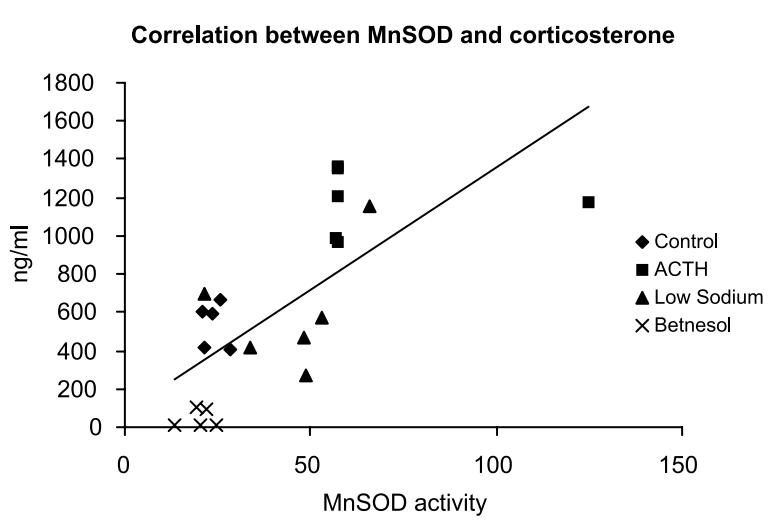

Correlation between MnSOD \& aldosterone

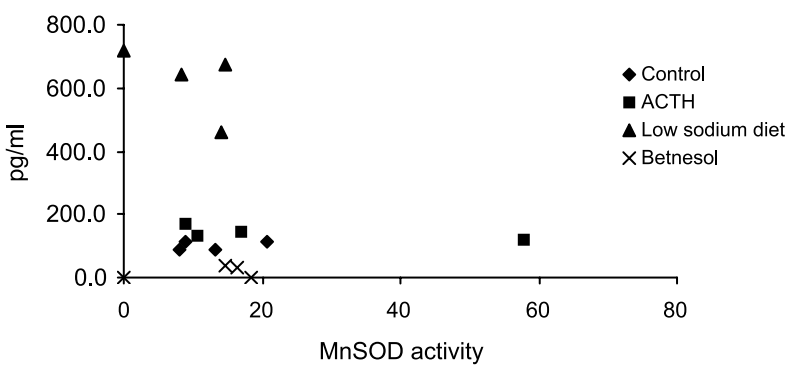

Figure 5 (a) Relationship between inner zone mitochondrial MnSOD activity and circulating corticosterone (Pearson correlation: $r=0.7 ; P=0.0002$ ). (b) Relationship between glomerulosa fraction mitochondrial MnSOD activity and circulating aldosterone concentrations $(r=-0 \cdot 22, \mathrm{NS})$. Betnesol, betamethasone.

Yet another interpretation arises from the work of Okada et al. (1995), who have postulated a key role for peroxidase-ascorbate reaction in the generation of progesterone from pregnenolone. The hydrogen peroxide generated by $\mathrm{MnSOD}$ in the mitochondrial matrix is believed to pass through the mitochondrial membrane and may be used to oxidise ascorbic acid to ascorbyl radicals. These radicals may in turn oxidise NADH to $\mathrm{NAD}^{+}$, which in turn is used as a hydrogen acceptor, enabling the conversion of pregnenolone to progesterone by $3 \beta$-hydroxysteroid dehydrogenase/isomerase. It is possible that such a mechanism may account for the relationship between plasma corticosterone and MnSOD, but it does not suggest why aldosterone output should be so independent of glomerulosa fraction MnSOD, which in any case is never high (Figs 5, 6). It is unclear why Okada et al. (1995) apparently rejected the concept that MnSOD is associated with NADP reduction, and hence mitochondrial hydroxylation.

Another possible function is suggested by recent publications showing that ROS may be important in cellular regulation, by functioning as signalling molecules. In particular, both the generation of ROS and their molecular targets in the actions of angiotensin II on vascular smooth muscle cells have been studied intensively (Griendling et al. 2000). However, the possibility that corticotrophin may similarly signal via ROS has not been substantiated in the published literature, although the results presented herein, identifying MnSOD as a corticotrophin-induced component in the fasciculata/reticularis of the rat adrenal cortex, suggest that this is a possibility.

None of these theories is entirely satisfactory, however, for they do not address the specificity of the responses, in that it is specifically MnSOD that is affected by the treatments, and that the effects occur specifically in fasciculata/reticularis cells (Figs 3-5). It is intriguing that Okada et al. (1995) have associated MnSOD with the tubulovesicular conformation of mitochondria characteristic of the zonae fasciculata/reticularis in the rat, and we have argued that this morphology is associated, not only with the production of corticosterone, but also with the generally high level of steroidogenesis in these cells (Vinson 2004). All this suggests that MnSOD has a highly specific function in the regulation of fasciculata function and glucocorticoid secretion by corticotrophin. A role for MnSOD must be postulated that explains such specificity.

There remain two features of these findings that suggest more complex regulation. One is that a low-sodium diet, normally without effect on the adrenocortical inner zones, stimulates inner zone MnSOD activity (Fig. 3). Apart from anything else, this strongly suggests an integration between the functions of the glomerulosa, normally considered the part of the gland responsive to the sodium status, and the fasciculata, normally not regarded as sodium sensitive, although we have argued that it must be (Vinson et al. 1995). The second feature is that betamethasone treatment has a complex action in that, like ACTH, it enhances expression of the $75 \mathrm{kDa}$ isoform (Fig. 6), although clearly suppressing plasma corticosterone and, presumably, endogenous ACTH (Fig. 2). One interpretation here is that part of the action of ACTH may be indirect, as glucocorticoids are known to induce MnSOD in some tissues such as glomeruli (Kawamura et al. 1991) although they are inhibitory in many others, including hepatocytes, macrophages and intestinal epithelial cells (Valentine \& Nick 1994). Hence betamethasone, although suppressing corticosterone, does not suppress MnSOD activity to the same extent (Fig. 3).

Taken together, the data strongly suggest a highly specific role for MnSOD activity in the inner zones of the rat adrenal. On balance, we think this is more likely to be related to aspects of steroidogenesis that are specific to the inner adrenocortical zones, fasciculata and reticularis. These links require further investigation.

\section{Funding}

The authors declare that there is no conflict of interest that would prejudice the impartiality of this scientific work. 
(a) Example blots

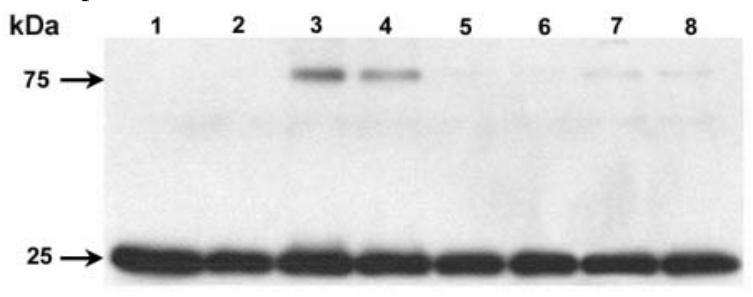

Densitometry

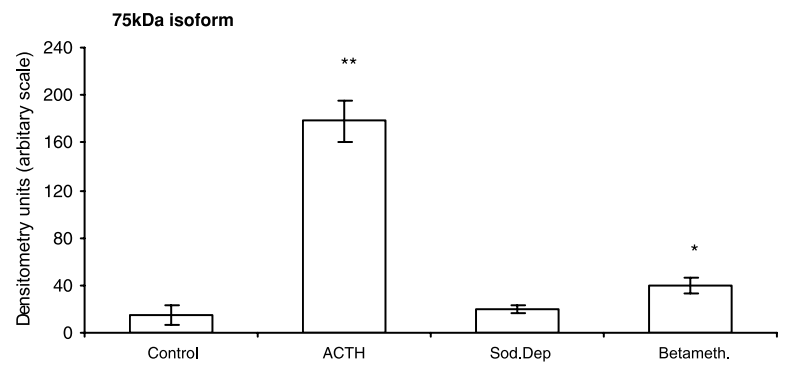

$25 \mathrm{kDa}$ isoform

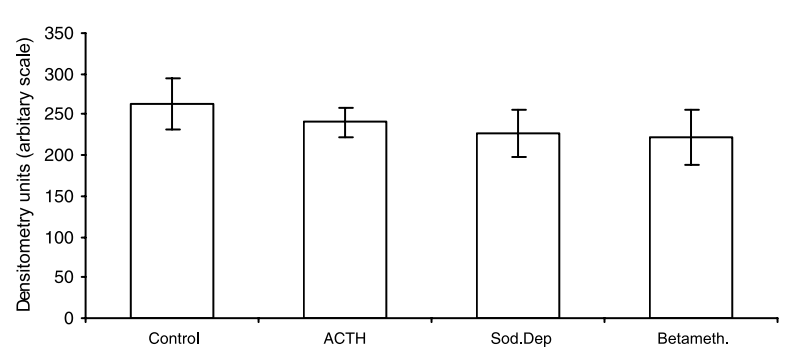

(b) Example blots

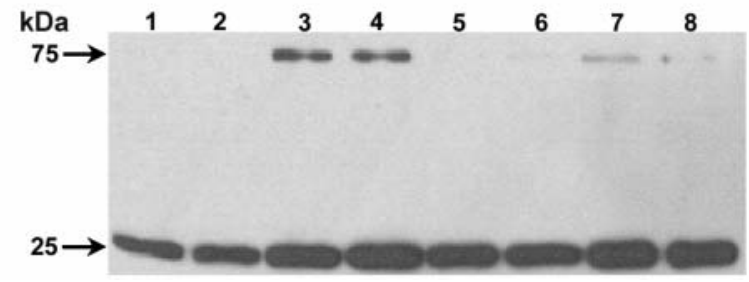

Densitometry

$75 \mathrm{kDa}$ isoform

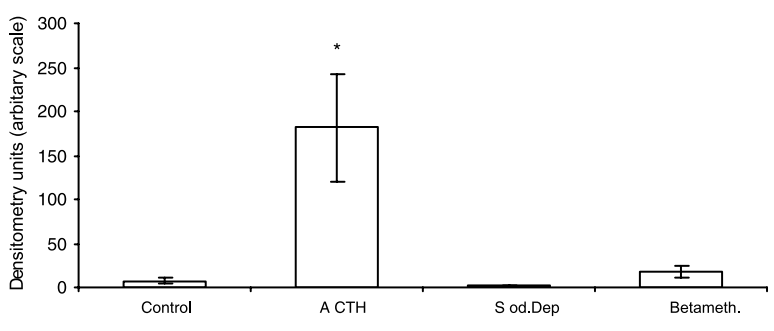

$25 \mathrm{kDa}$ isoform

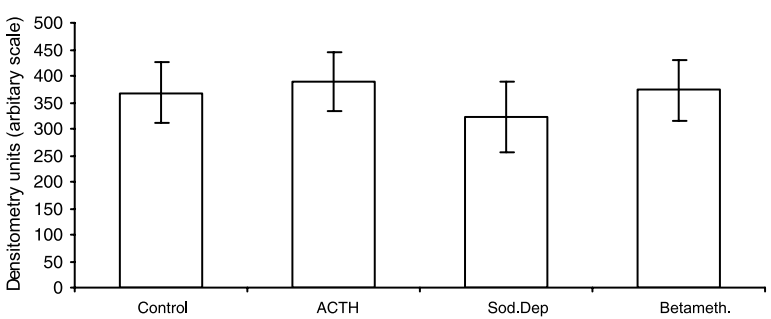

Figure 6 (a) Immunoblotting analysis of immunoreactive MnSOD in mitochondria from rat adrenal inner zones. Example blots: two isoforms were seen, at approximately $25 \mathrm{kDa}$ and $75 \mathrm{kDa}$. Densitometry: expression of the $75 \mathrm{kDa}$ isoform was induced by ACTH and by betamethasone (Betameth.) (comparison with controls: ${ }^{*} P<0 \cdot 05,{ }^{*} P<0 \cdot 01$, $t$-test with Bonferroni correction, $\left.n=4\right)$, whereas the $25 \mathrm{kDa}$ isoform was unaffected by the treatments. (b) Immunoblotting analysis of immunoreactive MnSOD in mitochondria from rat glomerulosa fraction. Example blots: as in the inner zone fractions, two isoforms were seen, at approximately $25 \mathrm{kDa}$ and $75 \mathrm{kDa}$. Densitometry: expression of the $75 \mathrm{kDa}$ isoform was induced by ACTH and by betamethasone (comparison with controls: ${ }^{*} P<0 \cdot 05$, $t$-test with Bonferroni correction, $n=4)$, whereas the $25 \mathrm{kDa}$ isoform was unaffected by the treatments. Sod. Dep., low-sodium diet.

\section{References}

Azhar S, Cao L \& Reaven E 1995 Alteration of the adrenal antioxidant defense system during aging in rats. Journal of Clinical Investigation 96 1414-1424.

Chayen J, Daly JR, Loveridge N \& Bitensky L 1976 The cytochemical bioassay of hormones. Recent Progress in Hormone Research 32 33-79.

Chinn AM, Ciais D, Bailly S, Chambaz E, LaMarre J \& Feige JJ 2002 Identification of two novel ACTH-responsive genes encoding manganese-dependent superoxide dismutase (SOD2) and the zinc finger protein TIS11b [tetradecanoyl phorbol acetate (TPA)inducible sequence 11b]. Molecular Endocrinology 16 1417-1427.

Gamaley IA \& Klyubin IV 1999 Roles of reactive oxygen species: signaling and regulation of cellular functions. International Review of Cytolology 188 203-255.

Griendling KK, Sorescu D \& Ushio-Fukai M 2000 NAD(P)H oxidase - role in cardiovascular biology and disease. Circulation Research 86 494-501.
Halder SK, Takemori H, Hatano O, Nonaka Y, Wada A \& Okamoto M 1998 Cloning of a membrane-spanning protein with epidermal growth factor-like repeat motifs from adrenal glomerulosa cells. Endocrinology $1393316-3328$.

Hanukoglu I \& Rapoport R 1995 Routes and regulation of NADPH production in steroidogenic mitochondria. Endocrine Research 21 231-241.

Hornsby PJ, Harris SE \& Aldern KA 1985 The role of ascorbic acid in the function of the adrenal cortex: studies in adrenocortical cells in culture. Endocrinology 117 1264-1271.

Kawamura T, Yoshioka T, Bills T, Fogo A \& Ichikawa I 1991 Glucocorticoid activates glomerular antioxidant enzymes and protects glomeruli from oxidant injuries. Kidney International $\mathbf{4 0}$ 291-301.

Kitabchi AE 1967 Ascorbic acid in steroidogenesis. Nature 215 1385-1386.

Lowry OH, Rosebrough NJ, Farr AL \& Randall RJ 1951 Protein measurement with the folin phenol reagent. Journal of Biological Chemistry 193 265-275. 
McCord JM \& Fridovich I 1969 Superoxide dismutase. An enzymic function for erythrocuprein (hemocuprein). Journal of Biological Chemistry 244 6049-6055.

Okada T, Sasaki J, Nomura T, Watanabe S, Matsuura J, Kanda S \& Sato EF 1995 Expression of manganese superoxide dismutase mRNA in the rat adrenal cortex is associated with the occurrence of mitochondrial vesicular cristae. Acta Histochemica et Cytochemica 28 389-395.

Raza FS, Takemori H, Tojo H, Okamoto M \& Vinson GP 2001 Identification of the rat adrenal zona fasciculata/reticularis specific protein, inner zone antigen (IZAg), as the putative membrane progesterone receptor. European Journal of Biochemistry $\mathbf{2 6 8}$ 2141-2147.

Sahut-Barnola I, Lefrancois-Martinez AM, Jean C, Veyssiere G \& Martinez A 2000 Adrenal tumorigenesis targeted by the corticotropin-regulated promoter of the aldo-keto reductase akr1b7 gene in transgenic mice. Endocrine Research 26 885-898.

Sayers MA, Sayers G \& Woodbury LA 1948 The assay of adrenocorticotrophic hormone by the ascorbic acid depletion method. Endocrinology 42 379-393.

Spitz DR \& Oberley LW 1989 An assay for superoxide-dismutase activity in mammalian tissue-homogenates. Analytical Biochemistry 179 8-18.

Suwa T, Munea T, Moritaa H, Daidoa H, Saiob M \& Yasudaa K 2000 Role of rat adrenal antioxidant defense systems in the aldosterone turn-off phenomenon. Journal of Steroid Biochemistry and Molecular Biology 73 71-78.
Valentine JF \& Nick HS 1994 Glucocorticoids repress basal and stimulated manganese superoxide dismutase levels in rat intestinal epithelial cells. Gastroenterology 107 1662-1670.

Vinson GP 2004 Glomerulosa function and aldosterone synthesis in the rat. Molecular and Cellular Endocrinology 217 59-65.

Vinson GP, Whitehouse BJ \& Hinson JP 1992 The Adrenal Cortex. Englewood Heights, NJ: Prentice-Hall.

Vinson GP, Teja R, Ho MM \& Puddefoot JR 1995 A two cell type theory for aldosterone biosynthesis: the roles of $11 \beta$-hydroxylase and aldosterone synthase, and a high capacity, tightly binding steroid carrier (TBSC) for 18-hydroxydeoxycorticosterone. Journal of Endocrinology 144 359-368.

Weisiger RA \& Fridovich I 1973a Mitochondrial superoxide dismutase. Site of synthesis and intramitochondrial localization. Journal of Biological Chemistry 248 4793-4796.

Weisiger RA \& Fridovich I $1973 b$ Superoxide dismutase. Organelle specificity. Journal of Biological Chemistry 248 3582-3592.

White CW, Nguyen DDH, Suzuki K, Taniguchi N, Rusakow LS, Avraham KB \& Groner Y 1993 Expression of manganese superoxide-dismutase is not altered in transgenic mice with elevated level of copper-zinc superoxide-dismutase. Free Radical Biology and Medicine 15 629-636.

Yanagibashi K, Kobayashi Y \& Hall PF 1990 Ascorbate as a source of reducing equivalents for the synthesis of aldosterone. Biochemical and Biophysical Research Communications 170 1256-1262.

Received 18 March 2004

Accepted 17 September 2004 